\title{
Ankle Instability among Mid-Foot Deformity Patients
}

Fiza Saleem ${ }^{1}$, Shoaib Waqas ${ }^{2}$, Muhammad Tariq ${ }^{3}$, Hina Gul ${ }^{4}$, Hafiz Muhammad Asim ${ }^{5}$

\footnotetext{
${ }^{1}$ Student, Lahore College of Physical Therapy, LMDC, Lahore

${ }^{2}$ Associate Professor, Lahore College of Physical Therapy, LMDC, Lahore

${ }^{3}$ Assistant Professor, Lahore College of Physical Therapy, LMDC, Lahore

${ }^{4}$ Assistant Professor, Lahore College of Physical Therapy, LMDC, Lahore

${ }^{5}$ Professor, Lahore College of Physical Therapy, LMDC, Lahore
}

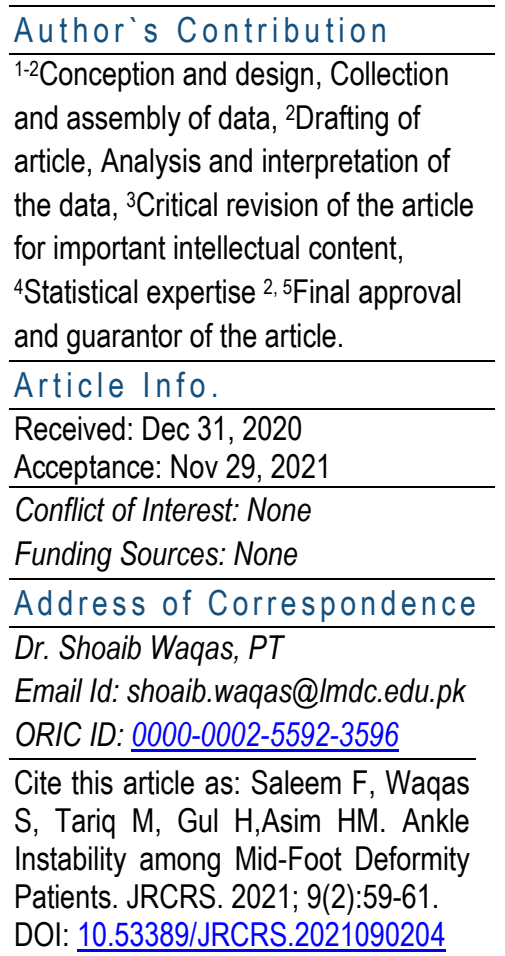

\section{A B S T R A C T}

Objective: To find out ankle instability among midfoot deformity patients

Methodology: A six-month descriptive cross-sectional study was conducted at Ghurki Trust and Teaching Hospital, Children's Hospital, and the Institute of Child Health in Lahore, with 96 individuals (64 men and 32 females) from August 2018 to January 2019. The inclusion criteria were children aged 1-6 years after Ponesti method and children with resistant or recurrent CTEV. The sample was collected by convenient sampling technique. The Ethical Committee of the Lahore College of Physical Therapy granted permission. Ankle instability of each patient was assessed with Cumberland Ankle Instability Tool questionnaire. Statistical Package for Social Sciences (SPSS) version 23 was used to enter and analyze data.

Results: The Cumberland Ankle Instability Tool questionnaire has 9- items 30-point scale where less than 27 score shows ankle instability. The study found that 88 individuals had ankle instability and 8 had ankle stability out of a total of 96 patients.

Conclusion: Maximum patients of mid-foot deformity were presented with ankle instability. of lack of knowledge of when to use hearing protection.

Keywords: Ankle instability, Deformity.

\section{Introduction}

Congenital talipes equinovarus (CTEV) is the most prevalent developmental problem with the deformities of foot and ankle which include equines and varus of hind foot, with apparent supination and adductus of midfoot and forefoot. ${ }^{1}$ CTEV has the frequency of 1.6 per 1000 live births. ${ }^{2}$

Contractures of ligamentous, capsular and musculotendinous structures lead to the subluxations at talonavicular, calcaneocuboid and talocalneal joints. The most commonly tightened structures are the sheaths of the tibialis posterior and peroneal tendons, as well as calcaneofibular and plantar based talocalcanenavicular ligaments, which reduced the elasticity in lateral ligaments and capsules compared to medial structures, reinforcing the theory of postero-lateral tethering. ${ }^{3}$ The inadequacy of lateral ligaments( anterior talofibular and Calcaneofibular ligaments) and varus deformity at hind-foot lead to chronic lateral instability at ankle joint. ${ }^{4}$ Ankle instability can be mechanical or functional; mechanical instability can be determined by a physical examination, whereas functional instability is determined by patient reports or complaints. ${ }^{5}$

The recurrence or persistent deformities of CTEV are rare after the age of 4-5 years and usually did not occur after the age of 7 -years. ${ }^{6}$ The Cumberland Ankle Instability Tool (CAIT) questionnaire was constructed in 2018. The validity of CAIT is 0.96 and the interpretation of CAIT calculated by Hiller et al. a cut-off value less than 27 , it is used to indicate ankle instability. ${ }^{7}$ 
The rationale of this study is to provide physiotherapist with the idea that which age group in children of CTEV require what extent of therapy as it would provide the data about prevalence of patients in respective age groups that is which age group have more instability would be determined.

\section{Methodology}

A six-month descriptive cross-sectional study was conducted at Ghurki Trust and Teaching Hospital, Children's Hospital, and the Institute of Child Health in Lahore, with 96 individuals (64 men and 32 females) from August 2018 to January 2019. The inclusion criteria were children aged 1-6 years after Ponesti method and children with resistant or recurrent CTEV. The sample was collected by convenient sampling technique. The Ethical Committee of the Lahore College of Physical Therapy granted permission. Ankle instability of each patient was assessed with Cumberland Ankle Instability Tool questionnaire. Statistical Package for Social Sciences (SPSS) version 23 was used to enter and analyze data. The study variables were demonstrated in the form of descriptive statistics (tables, graphs and percentage).

\section{Results}

Out of 96 patients the children having age between 16 years presented with mean age and standard deviation $9.88+1.975 .66 .7 \%$ were male $(n=64)$ and $33.3 \%$ were female $(n=32)$ suffered from midfoot deformities. Out of 96 patients 88 presented with ankle instability with score less than 27 on CAIT with total percentage is $91.7 \%, 8$ patients presented with ankle stability with score greater than 27 on CAIT with total percentage is $8.3 \%$.

\section{Age of patients}

\begin{tabular}{lcc}
\hline Age-Range & Frequency & Percent \\
\hline 1-2 years & 64 & 66.7 \\
\hline $3-4$ years & 30 & 31.3 \\
\hline 5-6 years & 2 & 2.1 \\
\hline Total & 96 & 100.0 \\
\hline
\end{tabular}

Gender of the patients

\begin{tabular}{lcc}
\hline Gender & Frequency & Percent \\
\hline Male & 64 & 66.7 \\
\hline Female & 32 & 33.3 \\
\hline Total & 96 & 100.0 \\
\hline
\end{tabular}

Cumberland ankle instability tool

\begin{tabular}{lcc}
\hline Parameter & Frequency & Percent \\
\hline Ankle Instability & 88 & 91.7 \\
\hline Ankle stability & 8 & 8.3 \\
\hline Total & 96 & 100.0 \\
\hline
\end{tabular}

\section{Discussion}

A study was conducted on the aspects residual deformity, epidemiology and patient reported outcome of clubfoot in which after the age of 3-4 years recurrence of deformities rarely occur. After the careful data analysis of present study results showed that children after the age of 3-4 years who presented with CTEV rarely reported with recurrence of deformities. ${ }^{6}$

Another study was conducted on chronic lateral ankle instability has been associated with hind-foot varus deformity which was one of the component of CTEV deformities. The findings were consistent with the current study's findings suggesting a greater frequency of lateral ankle instability in children aged $1-6$ years. ${ }^{4}$

A systematic review conducted to see the factors which contributed to ankle instability concluded as dynamic balance, reaction time and strength deficits leads towards ankle instability which indirectly supports the current study as in mid foot deformity patients, dynamic balance and strength deficits causes tissue loading resulting ankle joint instability. ${ }^{8}$

The Cumberland ankle instability tool was tested in a Dutch population who were positive and negative cases of ankle instability. The results suggest that the tool is valid and reliable in assessing ankle instability and distinguishing between functionally unstable and stable ankles. The results of this previous study support the results of present study and its effectiveness. $^{9}$

A systematic review conducted to see either Chronic Ankle Instability Leads to Lower Extremity Kinematic Changes or not. The conclusion of these studies was that chronic ankle instability subjects had same hip flexion, decreased knee flexion and decreased dorsi-flexion which definitely affects the kinematic chain resultant as loading in whole limb as in mid foot deformity patients..$^{10}$

One of the most surprising aspects of the current study was that the children with ankle instability did not experience discomfort during regular activities.

$\frac{\text { Conclusion }}{\text { Maximum patients of mid-foot deformity were }}$
presented with ankle instability. Different aspects of Cumberland ankle instability tool highlighted that the mechanics of forefoot changed which causes instability. 


\section{References}

1. Paton $R$, Choudry Q. Neonatal foot deformities and their relationship to developmental dysplasia of the hip: an 11year prospective, longitudinal observational study. The Journal of bone and joint surgery British volume. 2009;91(5):655-8.

2. Smythe T, Kuper H, Macleod D, Foster A, Lavy C. Birth prevalence of congenital talipes equinovarus in low-and middle-income countries: a systematic review and meta-analysis. Tropical medicine \& international health. 2017;22(3):269-85.

3. Eastwood DM. The clubfoot: congenital talipes equinovarus. Children's Orthopaedics and Fractures: Springer; 2010. p. 541-58.

4. Vienne P, Schöniger R, Helmy N, Espinosa N. Hindfoot instability in cavovarus deformity: static and dynamic balancing. Foot \& ankle international. 2007;28(1):96-102.

5. Al-Mohrej OA, Al-Kenani NS. Chronic ankle instability: Current perspectives. Avicenna journal of medicine. 2016;6(4):103.
6. Wallander HM. Congenital clubfoot: Aspects on epidemiology, residual deformity and patient reported outcome. Acta orthopaedica. 2010;81(sup339):1-25.

7. Hiller $\mathrm{CE}$, Refshauge $\mathrm{KM}$, Bundy $\mathrm{AC}$, Herbert $\mathrm{RD}$, Kilbreath SL. The Cumberland ankle instability tool: a report of validity and reliability testing. Archives of physical medicine and rehabilitation. 2006;87(9):1235-41.

8. Thompson C, Schabrun S, Romero R, Bialocerkowski A, van Dieen J, Marshall P. Factors contributing to chronic ankle instability: a systematic review and meta-analysis of systematic reviews. Sports Medicine. 2018;48(1):189-205.

9. Vuurberg $\mathrm{G}$, Kluit L, van Dijk CN. The Cumberland Ankle Instability Tool (CAIT) in the Dutch population with and without complaints of ankle instability. Knee Surgery, Sports Traumatology, Arthroscopy. 2018;26(3):882-91.

10. Theisen A, Day J. Chronic ankle instability leads to lower extremity kinematic changes during landing tasks: a systematic review. International journal of exercise science. 2019;12(1):24.

\section{Copyright Policy}

All Articles are made available under a Creative Commons "Attribution-NonCommercial $\mathbf{4 . 0}$ International" license. (https://creativecommons.org/licenses/by-nc/4.0/). Copyrights on any open access article published by Journal Riphah college of Rehabilitation Science (JRCRS) are retained by the author(s). Authors retain the rights of free downloading/unlimited e-print of full text and sharing/disseminating the article without any restriction, by any means; provided the article is correctly cited. JRCRS does not allow commercial use of the articles published. All articles published represent the view of the authors and do not reflect the official policy of IRCRC 